\title{
ANALISA KONSOLIDASI DI AREA NON SAND-KEY PADA AREAL REKLAMASI PROYEK PENGEMBANGAN PELABUHAN BELAWAN-PHASE I MENGGUNAKAN PLAXIS 2D DAN 3D
}

\author{
Melvi Maulita Napitupulu, Roesyanto dan Rudi Iskandar \\ Universitas Sumatera Utara, Indonesia \\ Email: melvimaulita17@gmail.com, roesyantos@yahoo.com dan \\ sipil.s2.usu@gmail.com
}

\begin{abstract}
Reclamation is one way to use land or waters that are used to create new land lands from the bottom of the waters. Sand key is the location where the sand replacement is carried out, at this location soft soil will be excavated from the sea level elevation to the elevation obtained. Then it will be backfilled using sand which has better characteristics. The function of this sand replacement is to withstand the pressure moving from the reclamation area to the shipping channel as a result of the reclamation process. This analysis aims to determine the size of the consolidation reduction using the finite element method with modeling in $2 D$ and 3D Plaxis, in the non-sand key area. The method used in this research is the finite element method using Plaxis $2 D$ and $3 D$. From the analysis results, it is found that the size of the reduction in Plaxis $2 D$ is 7,930 meters and from Plaxis $3 D$ analysis is 7,935 meters. The decrease that occurred according to settlement plate observations in the field was 7,850 meters. It can be concluded that there is a difference in subsidence due to laboratory data that does not represent the entire soil layer. Consolidation reduction with $2 D$ and $3 D$ Plaxis gives results closer to the decrease in field observations where the percentage differences in the decrease are $1.008 \%$ and $1.071 \%$.
\end{abstract}

Keywords: consolidation; sand-key; plaxis

\begin{abstract}
Abstrak
Reklamasi adalah salah satu cara untuk menggunakan lahan atau perairan yang digunakan untuk pembuatan lahan daratan baru dari dasar perairan. Sand key adalah lokasi di mana sand replacement dikerjakan, pada lokasi ini tanah lunak akan digali dari elevasi permukaan dasar laut sampai elevasi yang didapatkan. Kemudian akan ditimbun kembali menggunakan pasir yang memiliki karakteristik yang lebih baik. Fungsi dari sand replacement ini adalah untuk menahan tekanan yang bergerak dari area reklamasi menuju ke alur pelayaran sebagai akibat dari proses reklamasi. Penelitian ini bertujuan untuk mengetahui besar penurunan konsolidasi dengan menggunakan metode elemen hingga dengan pemodelan pada plaxis 2D dan 3D, di area non sand key. Metode yang digunakan dalam penelitian ini adalah metode elemen hingga menggunakan plaxis 2D dan 3D. Dari hasil analisis diperoleh bahwa besar penurunan pada plaxis 2D adalah 7,930 meter dan
\end{abstract}


dari analisis plaxis 3D adalah 7,935 meter. Penurunan yang terjadi menurut pengamatan settlement plate di lapangan adalah 7,850 meter. Dapat disimpulkan bahwa terdapat perbedaan penurunan akibat data laboratorium tidak mewakili keseluruhan lapisan tanah. Penurunan konsolidasi dengan plaxis $2 \mathrm{D}$ dan 3D memberikan hasil yang lebih mendekati penurunan hasil observasi di lapangan dimana persentasi perbedaan penurunan sebesar $1,008 \%$ dan $1,071 \%$.

Kata kunci: konsolidasi; sand-key; plaxis

\section{Coresponden Author}

Email: melvimaulita17@gmail.com

Artikel dengan akses terbuka dibawah lisensi

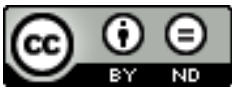

\section{Pendahuluan}

PT. Pelabuhan Indonesia (Pelindo) I sebagai badan usaha yang bergerak dalam bidang pelabuhan khususnya mengelola Pelabuhan Belawan, akan melakukan perluasan terminal peti kemas dengan cara mereklamasi daerah pantai yang berada di sekitar Pelabuhan Belawan. Hal ini dilakukan dengan pertimbangan utama untuk memperpendek jarak angkut antara tempat berlabuhnya kapal pengangkut peti kemas dengan terminal peti kemas yang baru.

Karakteristik lapisan tanah di areal pantai Pelabuhan Belawan merupakan tanah yang dominan adalah lempung yang cukup dalam dengan kandungan pasir halus yang cukup berarti. Lapisan tanah lunak yang berupa lempung (clay) mempunyai sifat-sifat antara lain cenderung sangat kompresibel (mudah mampat), tahanan geser tanah yang rendah, permeabilitas yang rendah dan mempunyai daya dukung yang rendah. Sifat mekanis tanah yang demikian ini adalah buruk dan kurang mampu menahan beban. Masalah umum yang terjadi pada saat konstruksi selesai adalah terjadinya proses konsolidasi akibat beban konstruksi yang melebihi tegangan prakonsolidasi lapisan lunak tersebut, sehingga menimbulkan penurunan. Pada pekerjaan proyek ini dilakukan dengan mengganti tanah dasar dengan pasir. Tanah lunak digali dan diisi dengan pasir yang berat jenisnya lebih besar dibandingkan tanah dasar.

Sand key adalah lokasi di mana sand replacement dikerjakan, pada lokasi ini tanah lunak akan digali dari elevasi permukaan dasar laut sampai elevasi yang didapatkan. Kemudian akan ditimbun kembali menggunakan pasir yang memiliki karakteristik yang lebih baik. Fungsi dari sand replacement ini adalah untuk menahan tekanan yang bergerak dari area reklamasi menuju ke alur pelayaran sebagai akibat dari proses reklamasi.

Penggunaan sand replacement akan mempengaruhi proses konsolidasi di area yang akan direklamasi. Penggunaan software plaxis 2D dan 3D menggunakan metode elemen hingga untuk menganalisis pengaruh sand replacement ini terhadap penurunan tanah, tekanan air pori dan aliran tekanan di lapisan tanah. Metode perkuatan dengan menggunakan sand replacement ini pernah diteliti oleh (Zukri, A., Nazir, R., Shien C. 
dan Kok, E., 2018) yang menunjukkan bahwa metode alternatif ini dapat mengurangi penurunan tanah dan mengurangi kemungkinan kegagalan konstruksi.

Dalam penelitian ini, analisis dilakukan menggunakan metode elemen hingga dengan bantuan program plaxis 2D dan 3D (Xu, 2017) untuk mendapatkan besar penurunan dan waktu yang dibutuhkan untuk proses konsolidasi pada tanah lunak. Hasil dari pemodelan 2D dan 3D akan dibandingkan sehingga didapat hasil yang paling mendekati dengan kondisi lapangan. Penelitian ini bertujuan untuk mengetahui besar penurunan konsolidasi dengan menggunakan metode elemen hingga dengan pemodelan pada plaxis $2 \mathrm{D}$ dan $3 \mathrm{D}$, di area non sand key

\section{Metode Penelitian}

\section{A. Input Data dengan Program Plaxis}

Untuk memasukkan data perhitungan ke plaxis, dibutuhkan beberapa paramater propertis tanah. Parameter-parameter tersebut dapat diperoleh dari hasil pengujian laboratorium maupun korelasi empiris dari nilai N-SPT, jenis, konsistensi dan sifat-sifat materialnya. Parameter tanah yang digunakan dalam program Plaxis diantaranya yaitu:

a. Berat volume tanah kering/dry soil weight $\left(\gamma_{\mathrm{dry}}\right)$

b. Berat volume tanah basah/wet soil weight $\left(\gamma_{\text {wet }}\right)$

c. Permeabilitas arah horizontal/horisontal permeability $\left(\mathrm{k}_{\mathrm{x}}\right)$

d. Permeabilitas arah vertikal/vertical permeability $\left(\mathrm{k}_{\mathrm{y}}\right)$

e. Modulus young/young's modulus (E),

f. Poisson's ratio $(\mathrm{v})$

g. Kohesi/cohesion (c)

h. Sudut geser/friction angle $(\varphi)$

i. Sudut dilatasi/dilatancy angle $(\psi)$

j. Koefisien konsolidasi $\left(\mathrm{c}_{\mathrm{v}}\right)$

Data-data tersebut di atas dapat diperoleh melalui pengujian properties tanah di laboratorium teknik sipil. Data-data tersebut diatas akan dimasukkan kedalam lapisan-lapisan tanah yang sudah dimodelkan di program plaxis. Selain itu, dalam memodelkan elemen tanah pada program plaxis dapat dilakukan dalam dua kondisi. Adapun kedua kondisi tersebut ialah :

\section{Kondisi drained}

Kondisi drained merupakan kondisi untuk tanah yang memiliki permeabilitas besar seperti tanah pasir, tanah yang mengalami pembebanan sangat lambat, serta untuk menstimulasikan perilaku tanah dalam jangka panjang. Kondisi drained pada program Plaxis digunakan untuk mengatur tidak ada kenaikan tekanan air pori (pore water pressure) pada material tanah (Fauzan Nurul Fajri, 2017). 
2. Kondisi undrained

Kondisi undrained merupakan kondisi untuk tanah yang memiliki permeabilitas kecil seperti tanah lempung sehingga ketika diberikan excess pore water pressure tidak langsung terdisipasi atau teralirkan (Herdiyan Kurniawan, 2014).

\section{Hasil dan Pembahasan}

\section{A. Hasil}

Dari data laboratorium titik $\mathrm{BH}-02$ diperoleh data masing-masing sampel adalah sebagai berikut:

\section{Tabel 1}

Data hasil pengujian di laboratorium

\begin{tabular}{|c|c|c|c|c|c|c|c|}
\hline \multirow[b]{2}{*}{$\begin{array}{c}\text { Bore } \\
\text { Hole No }\end{array}$} & \multirow{2}{*}{$\begin{array}{c}\text { Kedalaman } \\
\text { Contoh Tanah } \\
\text { Uds Yang } \\
\text { Diambil }\end{array}$} & \multicolumn{2}{|c|}{$\begin{array}{c}\text { Data Triaxial } \\
\text { Compression Test }\end{array}$} & \multicolumn{2}{|c|}{$\begin{array}{c}\text { Consolidation } \\
\text { Test }\end{array}$} & \multicolumn{2}{|c|}{ Index Properties } \\
\hline & & $\begin{array}{l}\text { Cohesion } \\
\text { (C) } \\
\mathrm{Kg} / \mathrm{Cm}^{2}\end{array}$ & $\begin{array}{l}\text { Angle } \\
\text { Of Int. } \\
\text { Friction } \\
\text { (ळ) }\end{array}$ & $\mathrm{C}_{\mathbf{C}}$ & $\mathbf{E}_{\mathbf{o}}$ & $\begin{array}{c}\text { Wet } \\
\text { Density } \\
\left(\mathrm{T} / \mathbf{m}^{3}\right)\end{array}$ & $\begin{array}{c}\text { Dry } \\
\text { Density } \\
\left(\mathbf{T} / \mathbf{m}^{3}\right)\end{array}$ \\
\hline \multirow{4}{*}{$\mathrm{BH}-02$} & $4,55-5,00$ & 50,5 & 13,8 & 0,289 & 1,38 & 16,30 & 11,60 \\
\hline & $14,50-15,00$ & 5,3 & 14,7 & 1,165 & 3,39 & 13,10 & 5,83 \\
\hline & $25,50-26,00$ & 29,2 & 13,3 & 1,276 & 2,17 & 15,30 & 8,79 \\
\hline & $43,50-44,00$ & 16,9 & 21,7 & 0,880 & 1.74 & 16,80 & 11,03 \\
\hline
\end{tabular}

\section{Pemodelan Lapisan Tanah}

Pemodelan lapisan tanah yang dilakukan mengacu pada hasil pengujian SPT, dimana dalam menentukan suatu lapisan tanah, harus mempertimbangkan deskripsi tanah dan juga N-SPT (Ohoimas \& Hamdhan, 2015). Pada Tahapan ini dilakukan setting material sesuai dengan lapisan tanah dari hasil bore log di lapangan.

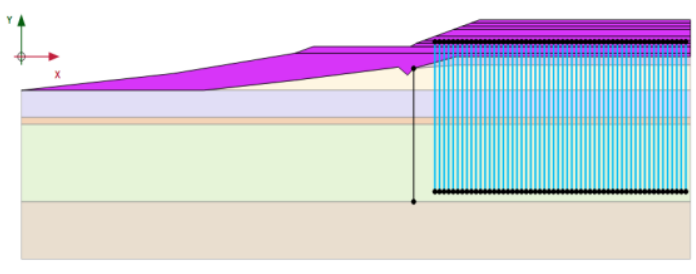

\section{Gambar 2}

Pemodelan geometri tanah pada Plaxis $2 D$ dengan PVD untuk model Plane Strain

Jumlah pembentukan mesh dapat dilihat pada Gambar 3, jumlah mesh yang diperoleh adalah 4.128 elemen dan 33.305 nodes. 
Analisa Konsolidasi Di Area Non Sand-Key pada Areal Reklamasi Proyek Pengembangan Pelabuhan Belawan-Phase I Menggunakan Plaxis 2D dan 3D

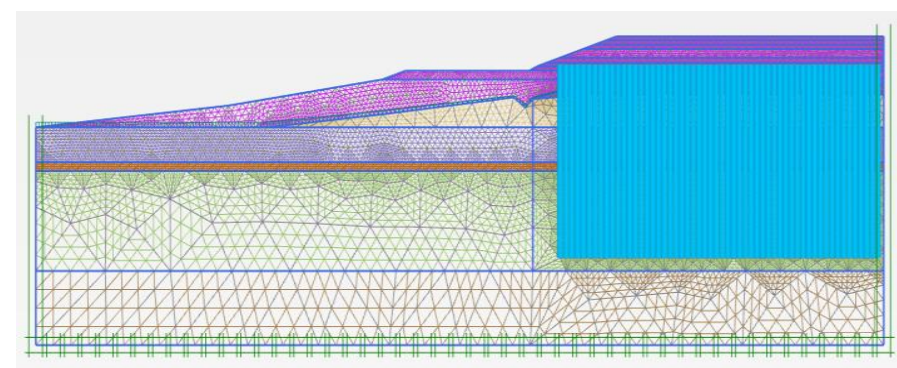

Gambar 3

Bentuk mesh yang dihasilkan

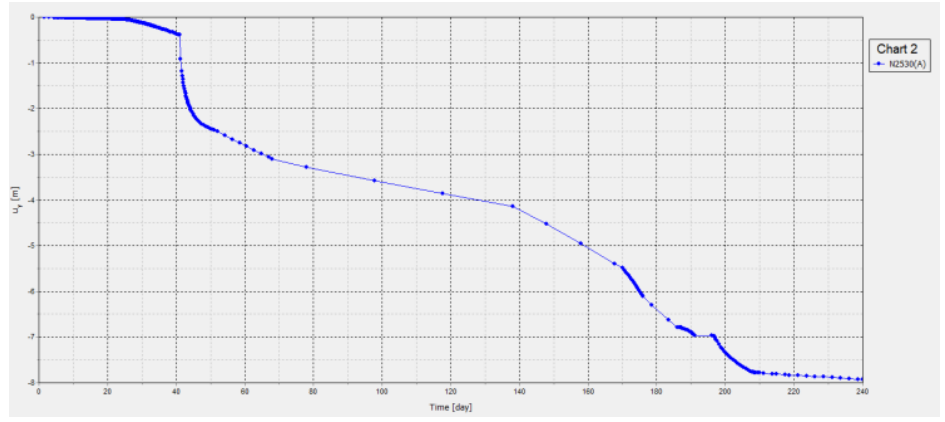

Gambar 4

Grafik hubungan antara penurunan vertikal dan waktu pada titik peninjauan

Dari hasil analisis plaxis didapat hasil penurunan sebesar 7,930 m sedangkan data yang didapatkan dilapangan besar penurunan sebesar 7,850 m. Adapun grafik perbandingan penurunan yang terjadi di lapangan dengan analisa Plaxis 2D dapat dilihat pada Gambar 5.

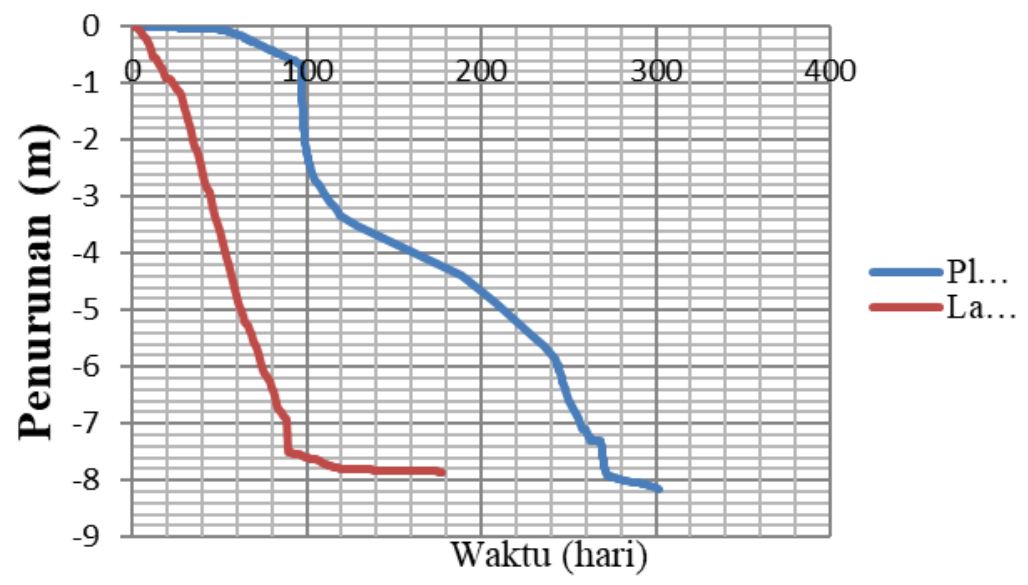

Gambar 5

Grafik Hubungan Perbandingan Penurunan yang Terjadi di Lapangan dengan Analisa Plaxis 2D 
2. Perhitungan dengan Plaxis 3D (Brinkgreve et al., 2016)

Pada perhitungan Plaxis 3D dihitung dengan efek smear zone, Permodelan direncanakan dengan 1 baris PVD atau dengan lebar permodelan 1,5 meter. Jenis pemodelan yang digunakan yaitu pemodelan full dengan 10 titik nodal. Lebar penampang yang ditinjau $190 \mathrm{~m}$ dengan perencanaan pemodelan PVD satu baris.

3. Pemodelan PVD (Putra, 2019)

Pemodelan PVD 1 baris dengan jarak 1,5 m menggunakan pola segitiga pada kedalaman 4,00 m sampai dengan 40,00 m. Pemodelan PVD dapat dilihat pada Gambar 6.

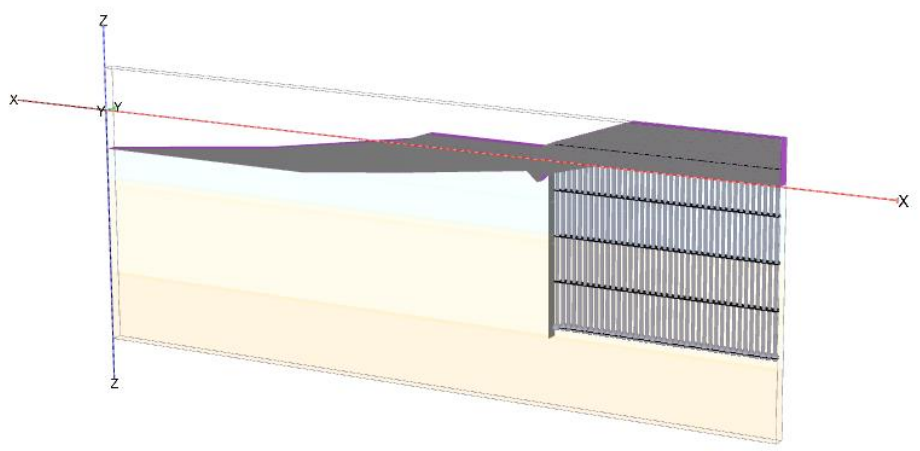

\section{Gambar 6}

Pemodelan PVD pada Plaxis 3D

\section{Penyusunan Jaring Elemen (Generate Mesh)}

Geometri disusun menjadi jaring elemen yang lebih kecil untuk melakukan hitungan. Setelah Tanah dan PVD dimodelkan, selanjutnya adalah pembentukkan mesh pada struktur tersebut, Jumlah pembentukan mesh dapat dilihat pada Gambar 7, jumlah mesh yang diperoleh adalah 131.976 elemen dan 178.291 node.

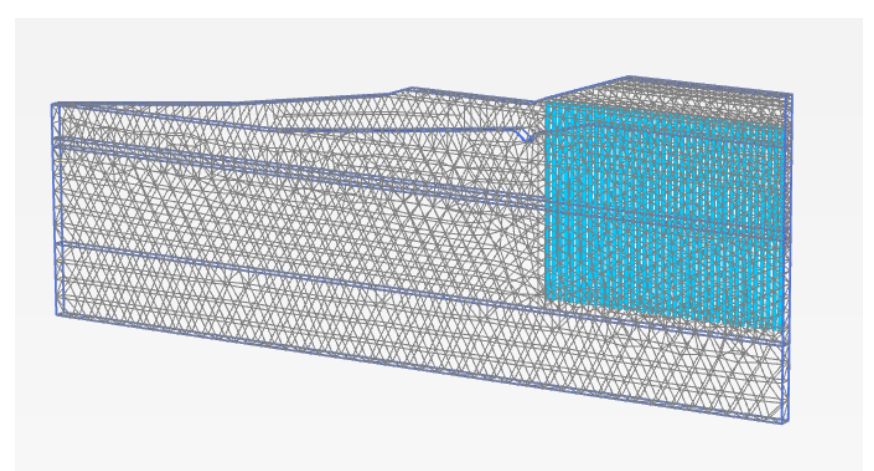

Gambar 7

Bentuk Mesh yang dihasilkan 


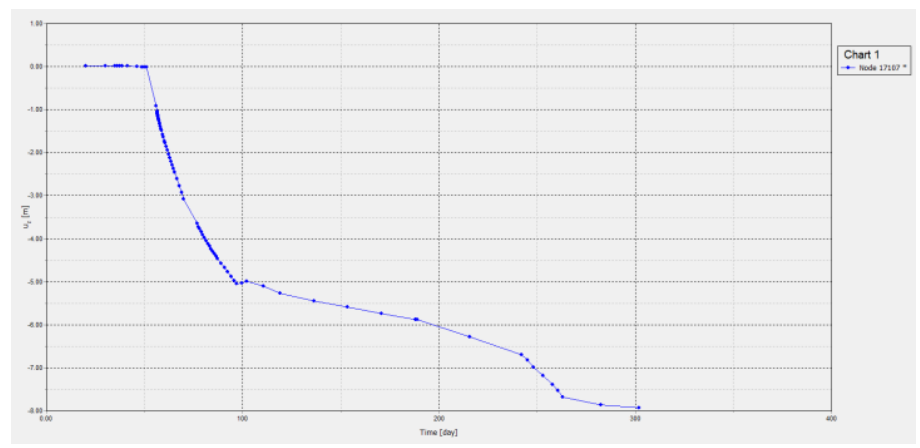

\section{Gambar 8}

Grafik penurunan Plaxis $3 D$

Dari hasil analisis plaxis 3D didapat hasil penurunan sebesar 7,935 m sedangkan data yang didapatkan di lapangan besar penurunan sebesar 7,85 $\mathrm{m}$, dan pada analisis Plaxis 2D diperoleh penurunan sebesar 7,930 m. Adapun perbandingan tersebut dapat dilihat pada gambar 8 .

Pada grafik dapat dilihat ketika pekerjaan galian dikerjakan, lapisan tanah mengalami penurunan akibat pegerakan tanah menuju galian yang terbuka. Namun lapisan tanah kembali mengalami kenaikan pada saat timbunan sand replacement dikerjakan, kenaikan ini disebabkan tegangan yang diberikan oleh tanah timbunan sehingga menyebabkan terangkatnya lapisan-lapisan yang belum ditimbun.

Ketika proses penimbunan dilakukan lapisan tanah yang ditinjau mengalami penurunan secara berangsur-angsur dan semakin cepat setelah dilakukan pemancangan Prefabricated Vertical Drain (PVD) (Chen, Shen, Yin, Xu, \& Horpibulsuk, 2016), (Indraratna, Bamunawita, Redana, \& McIntosh, 2003). Pemancangan PVD mengakibatkan kenaikan permeabilitas tanah dan proses keluarnya air pori tanah semakin cepat pula. Saat timbunan didiamkan, konsolidasi tanah mulai menunjukkan perlambatan sampai akhirnya tidak mengalami pertambahan penurunan lagi. 


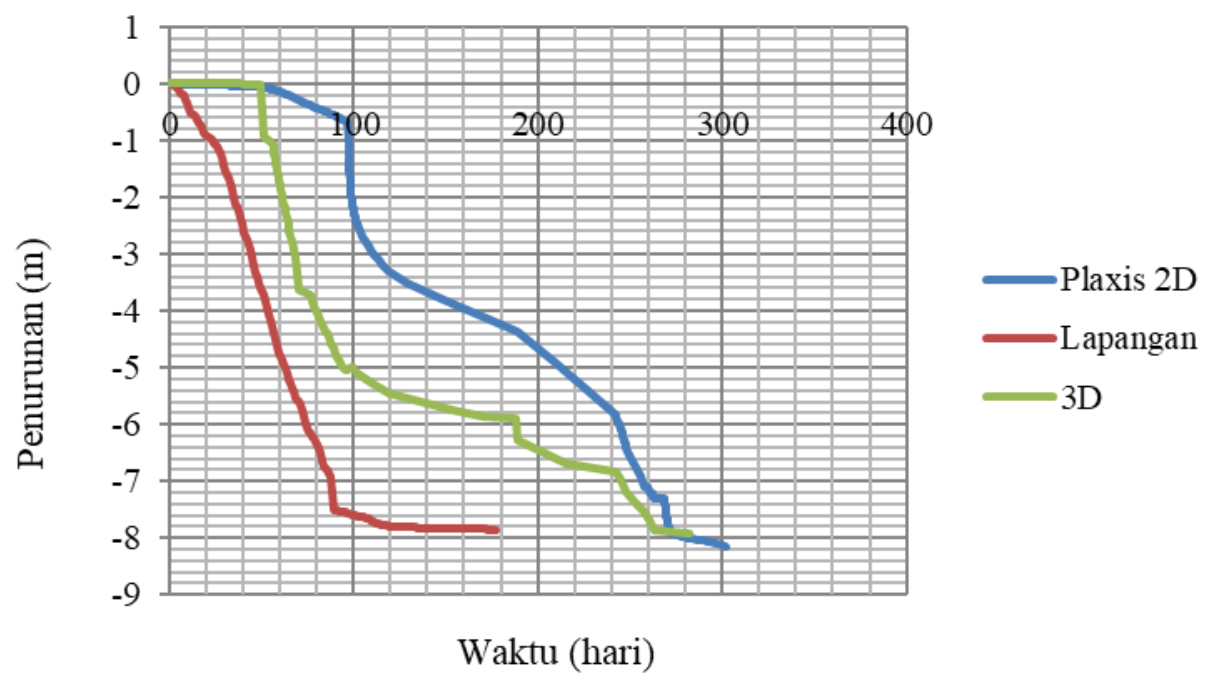

Gambar 9

Grafik Hubungan Perbandingan penurunan yang terjadi di lapangan dengan analisa Plaxis 2D dan Plaxis 3D

\section{B. Pembahasan}

1. Melalui analisa dan perhitungan, penurunan tanah adalah 7,829 meter. Hasil tersebut relatif mendekati hasil observasi penurunan aktual di lapangan, yaitu 7,850 meter dengan selisih 0,355 meter, karena data laboratorium tidak dapat merepresentasikan seluruh lapisan tanah di lapangan. Dengan Boring Log sampai kedalaman 60 meter hanya terdapat 4 sampel dengan ketebalan masingmasing 0,5 meter.

2. Penurunan yang didapat dari Plaxis $2 \mathrm{D}$ dan $3 \mathrm{D}$ berbeda, pada Plaxis 3D kondisinya lebih mendekati lapangan daripada di Plaxis 2D. Plaxis 3D menunjukkan bahwa pada saat konsolidasi terakhir, penurunan permukaan tanah tidak terlalu signifikan dan stabil. Sementara itu, Plaxis 2D menunjukkan bahwa pada periode konsolidasi akhir, penurunannya masih relatif besar.

3. Berdasarkan analisis yang dilakukan, pada pemodelan 2D terbentuk 4.128 elemen dan 33.305 node terbentuk, sedangkan pada pemodelan 3D terbentuk 131.976 elemen dan 178.291 node terbentuk. Dibandingkan dengan model 2D dengan elemen yang lebih sedikit, model 3D dengan lebih banyak elemen menghasilkan hasil yang lebih akurat. Semakin banyak jumlah elemen, semakin lama proses perhitungan dan analisisnya. Elemen dan node yang lebih sedikit berarti pemodelan 2D lebih mudah daripada 3D. Dibandingkan dengan 3D, keuntungan menggunakan Plaxis 2D adalah karena waktu kalkulasi yang lebih singkat, Plaxis 2D dapat menghasilkan beberapa iterasi dan kalkulasi secara bersamaan dengan Plaxis 3D (Bergado, Long, Chaiyaput, \& Balasubramaniam, 2018). 


\section{Kesimpulan}

Penurunan konsolidasi menggunakan teori analitis relatif mendekati penurunan hasil aktual di lapangan dengan persentasi perbedaan penurunan 0,260\%. Terdapat perbedaan penurunan akibat data laboratorium tidak mewakili keseluruhan lapisan tanah. Perhitungan Plaxis dilakukan dengan memperhitungkan efek smear zone, dimana efek smear zone merupakan area yang terjadi pada saat pemancangan PVD dilakukan.

Pada saat pekerjaan galian non sand key dilakukan tanah eksiting mengalami pergerakan kearah galian yang terbuka sehingga elevasi tanah eksisting mengalami penurunan. Ketika bekas galian non sand key ditimbun tanah mengalami tekanan dan bergerak kembali ke elevasi semula. Lapisan tanah mulai mengalami penurunan dengan cepat setelah dilakukan pemasangan PVD dan mulai stabil ketika konsolidasi akhir karena hilangnya air pori tanah. Hasil analisis konsolidasi menggunakan metode FEM dengan bantuan Plaxis 2D dan Plaxis 3D dan selisih penurunan konsolidasi yang terjadi dilapangan dengan analitik, Plaxis 2D, dan Plaxis 3D dapat dilihat pada tabel dibawah ini.

Tabel 2

Data hasil pengujian di laboratorium

\begin{tabular}{ccccc}
\hline No & Metode & $\begin{array}{c}\text { Penurunan } \\
(\mathbf{m})\end{array}$ & $\begin{array}{c}\text { Selisih dengan } \\
\text { lapangan } \\
\mathbf{( m )}\end{array}$ & $\begin{array}{c}\text { Persentase } \\
(\mathbf{\%})\end{array}$ \\
\hline 1 & Lapangan & 7,850 & & \\
\hline 2 & Analitis & 7,829 & 0,355 & 0,260 \\
\hline 3 & Plaxis 2D & 7,930 & 0,080 & 1,008 \\
\hline 4 & Plaxis 3D & 7,935 & 0,085 & 1,071 \\
\hline
\end{tabular}




\section{BIBLIOGRAFI}

Bergado, D. T., Long, P. V, Chaiyaput, S., \& Balasubramaniam, A. S. (2018). Prefabricated vertical drain (PVD) and deep cement mixing (DCM)/stiffened DCM (SDCM) techniques for soft ground improvement. IOP Conference Series: Earth and Environmental Science, 143(1), 12002. IOP Publishing.

Brinkgreve, R. B. J., Kumarswamy, S., Swolfs, W. M., Waterman, D., Chesaru, A., \& Bonnier, P. G. (2016). PLAXIS 2016. PLAXIS Bv, the Netherlands.

Chen, Jun, Shen, Shui Long, Yin, Zhen Yu, Xu, Ye Shuang, \& Horpibulsuk, Suksun. (2016). Evaluation of effective depth of PVD improvement in soft clay deposit: a field case study. Marine Georesources \& Geotechnology, 34(5), 420-430.

Fauzan Nurul Fajri, Rizqi. (2017). Analisis Stabilitas Tanah Pada Pondasi Telapak Dengan Varian Pemodelan Tanah Kondisi Drained Dan Undrained Menggunakan Program Bantu Plaxizs 8.2. Universitas Komputer Indonesia.

Herdiyan Kurniawan, Cepi. (2014). Perilaku galian pada tanah lunak dengan perkuatan sheet pile pada kondisi drained dan undrained ditinjau dari berbagai permodelan tanah. Universitas Komputer Indonesia.

Indraratna, Buddhima, Bamunawita, C., Redana, I. W., \& McIntosh, G. (2003). Modelling of prefabricated vertical drains in soft clay and evaluation of their effectiveness in practice. Proceedings of the Institution of Civil Engineers-Ground Improvement, 7(3), 127-137.

Ohoimas, Muhammad Yanuar, \& Hamdhan, Indra Noer. (2015). Analisis Konsolidasi dengan Menggunakan Metode Preloading dan Vertical Drain pada Areal Reklamasi Proyek Pengembangan Pelabuhan Belawan Tahap II (Hal. 1-11). RekaRacana: Jurnal Teknil Sipil, 1(1), 1.

Putra, Alfred Siemarga. (2019). Pemodelan emabankment di atas tanah lunak dengan dan tanpa PVD dan mekanisme lintasan tegangannya.

Xu, Binbin. (2017). Influence of Surcharge Preloading Improvement on Surrounding Environment Based on Plaxis 3D. IOP Conference Series: Earth and Environmental Science, 100(1), 12108. IOP Publishing.

Zukri, A., Nazir, R., Shien C. dan Kok, E. (2018). The Settlement Evaluation of Improved Soft Clay Using LECA Replacement Technique. Geotechnical Engineering Journal of the SEAGC, Conference Paper November 2018. 